\title{
El secreto médico y el consentimiento informado en los informes periciales.
}

Medical secret and informed consent in medical expertise.

IV JORNADAS ANDALUZAS SOBRE VALORACIÓN DEL DAÑO CORPORAL Sevilla, mayo-junio 2001

\section{E. Lachica López ${ }^{1}$}

\section{RESUMEN}

La regulación y aplicación tanto del secreto médico como del consentimiento del paciente en el ámbito de la actuación médica pericial encierra conflictos y dificultades importantes. En el presente trabajo se analiza la normativa existente para la profesión médica, poniéndose de manifiesto la inexistencia de regulación legal específica de la actividad pericial en lo que respecta a estos dos derechos fundamentales del paciente.

Palabras clave: secreto médico, consentimiento, actividad pericial.

\section{ABSTRACT}

Regulation and application of both medical secret and patient's consent in the expert medical practice has important difficulties. This paper analyses the legal regulations for the medical profession, and shows the nonexistence of specific norms in the expert's field activities in what concerns these patient's two fundamental rights.

Key words: medical secret, consent, expertise. 


\section{INTRODUCCIÓN:}

En el Derecho Procesal Español, la prueba pericial médica se encuentra incorporada a la Ley de Enjuiciamiento Criminal desde el primer texto (1892), en el que se contempla que es el medio de prueba de carácter personal consistente en la aportación al proceso por un tercero de una serie de conocimientos especializados o técnicos, que el juez no posee, con el fin de facilitarle la apreciación del hecho controvertido sometido a su consideración.

Es por ello que, entre los medios de prueba que regulan nuestras leyes, la pericial tiene un papel relevante no solo por su específica naturaleza, sino sobre todo porque mientras las demás pruebas (testigos, documentos, etc.) sirven para traer datos al proceso, la pericial opera sobre datos ya existentes, pero precisados de una ratificación científica, artística o práctica. De ahí que se diga que el perito no se sitúa, como el testigo, frente al juez para ser examinado, sino junto al juez, para examinar.

En definitiva, el objetivo de la pericia es el descubrir la verdad científica sobre unos hechos cuyo correcto conocimiento puede ser conveniente, necesario o imprescindible (según los casos) para imponer una sentencia justa (no olvidemos la conocida frase de Ambrosio Paré: "Los jueces deciden según se les informa").

Socialmente la idea predominante es que la Medicina es una ciencia asistencial, por lo que el perito es en muchas ocasiones considerado como un médico "de segunda" pues su labor no es la curativa que se espera del médico. Al respecto, el Profesor Gisbert definía el acto médico como "cualquier actividad investigadora, diagnóstica, terapéutica y rehabilitadora de la salud y/o enfermedad de la persona humana". Aunque el médico cuando es reclamado como perito no tiene una finalidad asistencial en su actuación, sino asesora o auxiliadora de la justicia, para cumplir tal misión necesita casi siempre o siempre de la realización de un diagnóstico clínico, que no cabe duda que es un acto médico. Ello no es óbice para que, si lo cree necesario, tenga el deber respecto al paciente de prestar sus servicios como médico y realizar en algunas ocasiones una labor orientadora desde el punto de vista terapéutico.

En definitiva, la actuación del perito médico debe aunar aquellos principios legales y morales vigentes para que la misión que ostenta sea conforme a las reglas del buen hacer profesional. Como médico que es está formado para tratar con el hombre, enfermo o no, lesionado o no, pero, indiscutiblemente, ser humano que requiere un trato digno y respeto a sus derechos como paciente.

Los problemas jurídicos por los que el médico puede ser llamado para asesorar a la justicia pueden afectar a los distintos órganos jurisdiccionales: penal, civil y laboral.

El ámbito civil tiene la finalidad de la defensa y conservación de los derechos de la persona, por lo que el médico puede ser llamado para evaluar el daño corporal, establecer la filiación, capacidad civil o responsabilidad civil profesional.

En el campo penal, el perito actúa estableciendo la valoración del daño corporal, la responsabilidad penal profesional o la imputabilidad.

En el mundo laboral, su actividad se encamina a establecer las limitaciones funcionales que presenta un trabajador para desempeñar las tareas fundamentales de su puesto de trabajo y la posible relación entre sus lesiones y el mismo.

Son claras las diferencias judiciales según los ámbitos en los que se desarrolle el procedimiento, pero lo que siempre será constante es que el informe pericial médico habrá de ser justo, ponderado y objetivo.

La actividad pericial médica presenta ciertas peculiaridades. Dos de ellas son precisamente el objeto de mi intervención: el consentimiento y el secreto. 
Aunque el médico perito no es escogido por el paciente, sino que le viene asignado por el juez, su abogado o su compañía de seguros, ello no es obstáculo para dejar de cumplir la primera de las obligaciones, cual es la de informarle de la misión encomendada y de quién proviene. También es la principal fuente de desacuerdo, por ser asumible la negativa del enfermo a ser examinado o a facilitar la información médica necesaria para efectuar el estudio de su caso. Por ello se requieren ciertas condiciones en el perito que permitan mantener un clima de relación cálido con el paciente, siendo su primera función el hacer comprender que su actuación va a estar cargada de imparcialidad, ecuanimidad y, en definitiva, que se va a comportar como un testigo atento al servicio del pleito, no al de las partes, por lo que no juega el papel de adversario.

Generalmente el consentimiento para la actuación pericial médica no suele ser formal en el sentido de ser expresado por escrito, tratándose de un consentimiento oral, tácito.

Desde el punto de vista civil, el consentimiento se estudia en la teoría general del contrato, que es como lo regula el Código Civil al definirlo, establecer sus requisitos y señalar los vicios que lo invalidan. Desde esta perspectiva se dice que el contrato de servicios médicos no tiene por objeto el cuerpo del enfermo, sino la prestación sanitaria del profesional y, en todo caso, el precio o los honorarios que el paciente satisface por la prestación del servicio. Es decir, siendo esencial que el paciente consienta sobre el objeto del contrato, o sea, sobre la actividad del profesional, el consentimiento se encontraría viciado si de la información recibida pudiera desprenderse que ha contratado movido por el error. El consentimiento informado se considera como un requisito legitimador de la libertad del consentimiento, de tal manera que, de forma análoga a lo que sucede con el consentimiento prestado con intimidación o miedo, sería nulo el consentimiento que no es auténticamente libre por defecto de información.

Para el derecho penal, en cambio, el consentimiento no existe como institución general, aunque se le menciona al tratar de diversos delitos como causa que excluye o limita la responsabilidad profesional. La Ley prevé que pueda constituir delito o falta la intervención profesional carente de verdadero consentimiento del paciente.

Aunque la normativa vigente en nuestro país sobre el consentimiento informado es de aplicación en la actividad clínica asistencial, en el campo de la peritación médica no debería obviarse, toda vez que pueden ser necesarias una serie de pruebas complementarias para poder establecer un correcto diagnóstico. Esta normativa es la siguiente:

- Artículo 12 de la "Carta de los Derechos y Deberes del Paciente" (I 984): "El paciente tiene derecho a recibir cuanta información desee sobre los aspectos de las actividades asistenciales que afecten a su proceso y situación personales".

- Consulta no 3 de la Fiscalía General del Estado (1985): "Para los objetos corporales fungibles (o regenerables) podrá ser eficaz el consentimiento expresado verbalmente; para los demás casos el consentimiento expreso deberá adoptar forma documental indubitada. Por lo demás, en cuanto el consentimiento forma parte de un negocio jurídico recepticio, la voluntad del titular ha de ser comunicada a su destinatario".

- Artículo 10.6 de la Ley General de Sanidad (1986): "El paciente tiene derecho a la libre elección entre las opciones que le presente el responsable médico de su caso, siendo preciso el previo consentimiento escrito del usuario para la realización de cualquier intervención, ..."

- Artículo 5 del Convenio de Oviedo (1997): "Una intervención en el ámbito de la sanidad sólo podrá efectuarse después de que la persona afectada haya dado su libre e inequívoco consentimiento. Dicha persona deberá recibir previamente una información adecuada acerca de la finalidad y naturaleza de la intervención..." 
- Código de Ética y Deontología (1999): El artículo 41 .2 (capítulo XVII: "Médicos peritos y funcionarios") establece: "El médico perito debe comunicar previamente al interesado el título en virtud del cual actúa, la misión que le ha sido encargada y por quién. Si el paciente se negara a ser examinado, el médico renunciará a hacerlo y se limitará a poner tal extremo en conocimiento del mandante".

A la vista de esta normativa se aprecia el vacío legal existente en el ejercicio pericial de la medicina quedando sólo sujeto a la norma deontológica, la cual no es aplicable en gran número de actuaciones periciales ( $p$. ej. las del médico forense).

No cabe duda de que el desarrollo de la actividad médico pericial está en pleno cambio, y aún queda mucho por hacer. Hay que cambiar muchas mentalidades, muchas pautas de comportamiento que faciliten el ejercicio de esta forma de medicina. La situación actual de las normas es lamentable. Urge una reglamentación en esta materia, son bastantes los foros en los que se ha recogido esta necesidad, pero la realidad es que la medicina pericial sigue siendo poco considerada por nuestros legisladores.

Otro aspecto discordante entre medicina pericial y asistencial que afecta a otro de los derechos fundamentales del paciente es el relativo al secreto médico.

Recordemos que el secreto médico sustenta la relación de confianza que se establece con el paciente. La comunicación de la intimidad personal, que es básica en Medicina, no sería posible sin la seguridad que éste le proporciona.

El concepto de confidencialidad está muy ligado al de intimidad. La confidencialidad consiste precisamente en guardar reserva sobre las informaciones que afectan a la vida privada de los individuos. ¿Por qué la confidencialidad es un deber moral? Cuatro son los posibles argumentos:

I. La obligación general de no perjudicar a las personas.

2. El compromiso o la lealtad hacia determinadas asociaciones o grupos humanos.

3. La promesa o la palabra dada a alguien.

4. Estar desempeñando profesiones de utilidad social. les sanitarios.

Y es de esta última razón de la que nace la obligación de confidencialidad a los profesiona-

La Constitución alude al secreto profesional a través de algunos artículos que protegen derechos fundamentales:

- Art. 18 (puntos I y 4)'. Garantiza el derecho al honor, a la intimidad personal y familiar y a la propia imagen, así como que se limitará el uso de la informática para garantizar el honor y la intimidad personal y familiar de los ciudadanos.

- Art. 20 (I.d) $)^{2}$. Reconoce la existencia y defensa del Secreto Profesional, indicando que la ley lo regulará dentro del ejercicio de la libertad de información.

- Art. $24(2)^{3}$. Establece que la ley regulará los casos en que, por razones de secreto profesional, no se estará obligado a declarar sobre hechos presuntamente delictivos.

Han pasado más de veinte años desde la aprobación del precepto constitucional, pese a ello todavía no existe una ley del Secreto Profesional en nuestro país, es más, tras la cuidadosa lec-

\footnotetext{
I Art. 18: 1. "Se garantizará el derecho al honor, la intimidad personal y familiar a la propia imagen". En el apartado 4 dice: "La Ley limitará el uso de la informática para garantizar el honor y la intimidad personal y familiar de los ciudadanos y el pleno ejercicio de sus derechos"

2 Art. 20.1.d: "... La ley regulará el derecho a la cláusula de conciencia y al secreto profesional en el ejercicio de estas libertades".

3 Art.24.2: "... La ley regulará los casos en que, por razones de parentesco o de secreto profesional, no se estará obligado a declarar sobre presuntos actos delictivos".
} 
tura del precepto constitucional se puede comprobar que el único secreto profesional contemplado es el correspondiente al ejercicio del periodismo. No obstante, algunos principios constitucionales han sido introducidos en la numerosa legislación sanitaria promulgada en los años siguientes.

Así, en el terreno administrativo encontramos:

- Los Estatutos de la Organización Médica Colegial, que consideran la infracción del secreto por culpa o negligencia con perjuicio para un tercero como falta grave, y su violación intencional como falta muy grave (artículo 644 - "de las faltas disciplinarias"-).

- La Ley General de Sanidad en su artículo I0.3 refleja el derecho de los pacientes a "... la confidencialidad de toda información relacionada con su proceso y con su estancia en instituciones sanitarias, públicas o privadas que colaboren con el sistema público" La misma Ley en su artículo 6I establece que deben "... quedar plenamente garantizados el derecho del enfermo a su intimidad personal y familiar y el deber de guardar el secreto por quién, en virtud de sus competencias, tenga acceso a la historia clínica".

- La Ley Orgánica 5/I992 de regulación del tratamiento automatizado de los datos de carácter personal (LORTAD), igualmente protege este derecho del paciente, calificando como infracción grave o muy grave su vulneración (artículo $43^{5}$ - tipos de infracciones-).

- El Real Decreto 994/I999 por el que se aprueba el Reglamento de medidas de seguridad de los ficheros automatizados que contengan datos de carácter personal determina las medidas de índole técnica y organizativa que garanticen la confidencialidad e integridad de la información con la finalidad de preservar el honor, la intimidad personal y familiar y el pleno ejercicio de los derechos personales frente a su alteración, pérdida, tratamiento o acceso no autorizado.

- Por otra parte, en el Convenio relativo a los Derechos Humanos y la Biomedicina ("Convenio de Oviedo", 1997), se protege el derecho al respeto ala vida privada de los ciudadanos cuando se trate de informaciones relativas a su salud.

En el ámbito civil, la Ley Orgánica I/I 982 de Protección Civil al honor, a la intimidad y a la propia imagen considera intromisión ilegítima "... la revelación de datos privados de una persona o familia conocidos a través de la actividad profesional u oficial de quién la revela".

Finalmente, en el derecho penal se han introducido como figuras delictivas la revelación del secreto profesional aunque de ello no se derive un daño, y el acceso a datos de carácter personal sin el consentimiento del afectado, imponiéndoles unas sanciones tan severas como las del homicidio debido a una imprudencia grave (artículos 1976, 1987 y 1998 del Código Penal).

\footnotetext{
${ }^{4}$ Artículo 64 (Estatutos Generales de la Organización Médica Colegial): "3. Son faltas graves: ... La infracción grave del secreto profesional, por culpa o negligencia, con perjuicio para tercero". En el punto 4 de este mismo artículo: "Son faltas muy graves: ... b) La violación dolosa del secreto profesional".

5 Artículo 43 (LORTAD): "3. Son infracciones graves: ... g) La vulneración del deber de guardar secreto, cuando no constituya infracción muy grave". "4. Son infracciones muy graves: g) La vulneración del deber de guardar secreto sobre los datos de carácter personal a que hacen referencia los apartados 2 y 3 del artículo 7" (ideología, religión, creencias, origen racial, salud y vida sexual).

6 Artículo197 (Código Penal).

1. El que, para descubrir los secretos o vulnerar la intimidad de otro, sin su consentimiento, se apodere de sus papeles, cartas, mensajes de correo electrónico o cualesquiera otros documentos o efectos personales o intercepte sus telecomunicaciones o utilice artificios técnicos de escucha, transmisión, grabación o reproducción del sonido o de la imagen, o de cualquier otra señal de comunicación, será castigado con las penas de prisión de uno a cuatro años y multa de doce a veinticuatro meses.

2. Las mismas penas se impondrán al que, sin estar autorizado, se apodere, utilice o modifique, en perjuicio de tercero, datos reservados de carácter personal o familiar de otro que se hallen registrados en ficheros o soportes informáticos, electrónicos o telemáticas, o en cualquier otro tipo de ter personal o familiar de otro que se hallen registrados en ficheros o soportes informaticos, electronicos o telemáticas, o en cualquier otro tipo de
archivo o registro público o privado. Iguales penas se impondrán a quien, sin estar autorizado, acceda por cualquier medio a los mismos y a quien los archivo o registro público o privado. Iguales penas se impondrán
altere o utilice en perjuicio del titular de los datos o de un tercero.

3. Se impondrá la pena de prisión de dos a cinco años si se difunden, revelan o ceden a terceros los datos o hechos descubiertos o las imágenes captadas a que se refieren los números anteriores.

Será castigado con las penas de prisión de uno a tres años y multa de doce a veinticuatro meses, el que, con conocimiento de su origen ilícito y sin haber tomado parte en su descubrimiento, realizare la conducta descrita en el párrafo anterior.
} 
El respeto del secreto profesional y el derecho a la intimidad constituyen obligaciones jurídicas ineludibles para los profesionales sanitarios, lo que debe conciliarse con el deber de colaboración y de lealtad a los Tribunales de Justicia.

Los problemas que surgen en este campo no suelen ser de una vulneración voluntaria del secreto, sino de una resistencia a revelar las confidencias del paciente.

En la labor de colaboración con la Administración de Justicia, la doctrina más autorizada considera que el médico, cuando se encuentre ante la tesitura de tener que prestar declaración acerca de hechos relativos a la intimidad del paciente, debería de ponderar qué deber ha de prevalecer. Por consiguiente, deberá valorar aquellos datos que no tengan que ver con la finalidad del proceso y que el secreto médico le obliga a reservar.

Los problemas se agudizan más por la ligereza con que, en ocasiones, se solicita el historial clínico de los pacientes. Por ello la primera cuestión que deberíamos plantear en sí, alegando el derecho al secreto médico con fines de protección de la intimidad del paciente, se podría resistir el requerimiento judicial.

La cuestión fue abordada por la más alta instancia de protección de los derechos humanos, el Tribunal de Estrasburgo, que ha establecido que:

I.- El acceso por parte del interesado a datos médicos que le conciernen está integrado dentro del derecho a un juicio equitativo cuando su conocimiento y utilización se hace necesario para la defensa de sus intereses en juicio ( $y$ ello aún cuando haya terceros interesados en el mantenimiento del secreto).

2.- El derecho a la intimidad no impide su uso en contra de la voluntad del afectado, siempre que se den las condiciones establecidas en el precepto. Esto es, se disponga de una previsión legislativa, y que tal medida sea necesaria en una sociedad democrática y proporcionada al fin legítimo pretendido, a cuyo efecto aparece de especial importancia la relevancia de la prueba que pretende obtenerse mediante la incorporación de los datos médicos al proceso.

En consecuencia, en la actuación del médico perito el secreto médico no se establece con las autoridades judiciales que hayan demandado la pericia. No obstante, y en todos los casos, tanto si el sujeto asiste de forma voluntaria como si la prueba ha de practicarse sin su consentimiento o incluso con oposición o indiferencia ante la misma, el perito debe informarle acerca de la prueba y prevenirle de alguna manera de la condición de auxiliar del juez, así como de la no obligación del secreto profesional de lo que se obtenga.

Las situaciones conflictivas que se plantean son dos:

- El INFORME MÉDICO-LEGAL: Tanto cuando actúa a instancia del juez por imperativo legal, como a petición del interesado, está relevado de guardar el secreto médico.

\footnotetext{
4. Si los hechos descritos en los apartados 1 y 2 de este artículo se realizan por las personas encargadas o responsables de los ficheros, soportes informáticos, electrónicos o telemáticas, archivos o registros, se impondrá la pena de prisión de tres a cinco años, y si se difunden, ceden o revelan los datos reservados, se impondrá la pena en su mitad superior.

5. Igualmente, cuando los hechos descritos en los apartados anteriores afecten a datos de carácter personal que revelen la ideología, religión, creencias, salud, origen racial o vida sexual, o la víctima fuere un menor de edad o un incapaz, se impondrán las penas previstas en su mitad superior. 6. Si los hechos se realizan con fines lucrativos, se impondrán las penas respectivamente previstas en los apartados 1 al 4 de este artículo en su mitad superior. Si además afectan a datos de los mencionados en el apartado 5, la pena a imponer será la de prisión de cuatro a siete años.

7 Artículo 198 (Código Penal): "La autoridad o Funcionario público que, fuera de los casos permitidos por la Ley, sin mediar causa legal por delito, y prevaliéndose de su cargo, realizare cualquiera de las conductas descritas en el artículo anterior, será castigado con las penas respectivamente previstas en el mismo, en su mitad superior y, además, con la de inhabilitación absoluta por tiempo de seis a doce años"

8 Artículo 199 (Código Penal): "1. El que revelare secretos ajenos, de los que tenga conocimiento por razón de su oficio o sus relaciones laborales, será castigado con la pena de prisión de uno a tres años y multa de seis a doce meses.

2. El profesional que, con incumplimiento de su obligación de sigilo o reserva, divulgue los secretos de otra persona, será castigado con la pena de prisión de uno a cuatro años, multa de doce a veinticuatro meses e inhabilitación especial para dicha profesión por el tiempo de dos a seis años".
} 
Las bases legales que soportan esta afirmación están recogidas en:

- Los artículos 412.19 (sobre la denegación de auxilio a la Justicia), 55010 y 55611 (sobre la desobediencia grave a la autoridad judicial) del Código Penal;

- Ley orgánica del Poder Judicial (artículo 1712);

- Los artículos $346^{13}$ y $357^{14}$ de la Ley de Enjuiciamiento Criminal (sobre la negativa al desempeño del cargo de perito);

- El artículo | | 15 de la Ley Orgánica 5/I992 de regulación del tratamiento automatizado de los datos de carácter personal (sobre la cesión de datos);

- Código Deontológico (artículo 1616).

- La OBTENCIÓN DE DATOS CLíNICOS PARA LA ELABORACIÓN DEL INFORME. El mayor problema se plantea cuando el perito médico es el de la parte contraria al lesionado. En este caso al perito se le pueden crear serias dificultades relacionadas tanto con el secreto profesional como con el consentimiento del lesionado.

A los únicos datos que pueden acceder las compañías son a los necesarios para el abono de gastos de asistencia sanitaria efectuados por terceros (sanidad pública o privada), como queda establecido en los convenios de asistencia sanitaria correspondientes, que permiten y obligan al centro asistencial a proporcionar a la compañía de seguros las facturas con todos los conceptos detallados, las lesiones de los lesionados en los partes de asistencia y un informe de la evolución de la lesión.

En estas situaciones conflictivas, si el caso ha llegado a la vida judicial, el perito accederá a la información que conste en el proceso y solicitará por esta misma vía lo que estime oportuno.

Pero la verdadera dificultad se presenta en la vía de convenio, cuando el lesionado no presta su consentimiento ni para el acceso a su historial, ni para su exploración. En estas ocasiones el perito se encuentra en una situación de impedimento absoluto para ejercer la función que tiene encomendada.

El médico o centro asistencial, fuera de las excepciones que marca la ley, no puede aportar datos del lesionado a no ser que su finalidad sea asistencial o se haga con el consentimiento del paciente. Dada la regulación legal del secreto, en estas situaciones, la única solución para el perito o para la compañía aseguradora es la de reclamar por la vía judicial. De actuar de otra forma (obteniendo los datos sin una finalidad asistencial y/o sin el consentimiento del paciente), se incurre en un delito de descubrimiento o de revelación de secretos o de permitir acceder a datos personales por el encargado de su custodia.

\footnotetext{
9 Art. 412.1 (CP). "El funcionario público que, requerido por autoridad competente, no prestare el auxilio debido para la Administración de Justicia u otro servicio público, incurrirá en las penas de multa de tres a doce meses y suspensión de empleo o cargo público por tiempo de seis meses a dos años".

10 Art. 550 (CP): "Son reos de atentado los que acometan a la autoridad, a sus agentes o funcionarios públicos, o empleen fuerza contra ellos, los intimiden gravemente o les hagan resistencia activa también grave, cuando se hallen ejecutando las funciones de sus cargos o con ocasión de ellas".

1 I Art. 556 (CP): "Los que, sin estar comprendidos en el artículo 550, resistieren a la autoridad o sus agentes, o los desobedecieren gravemente, en el ejercicio de sus funciones, serán castigados con la pena de prisión de seis meses a un año".

12 Art. 17 (LOPJ): "Todas las personas y entidades públicas y privadas están obligadas a prestar, en la forma que la Ley establezca, la colaboración requerida por los Jueces y Tribunales en el curso del proceso...".

13 Art. 346 (LE Crim): "En las ausencias, enfermedades y vacantes, sustituirá al médico forense otro profesor que desempeñe igual cargo en la misma población, y si no lo hubiese, el que el Juez designe, dando cuenta de ello al Presidente de la Audiencia de lo Criminal.

Lo mismo sucederá cuando por cualquier otro motivo no pudiese valerse el Juez instructor del Médico forense. Los que se negaren al cumplimiento de este deber o lo eludieren, incurrirán en multa de 125 a 500 pesetas".

14 Art. 357 (LE Crim): "Los indicados Profesores prestarán este servicio en el concepto de peritos titulares, y no podrán negarse a efectuarlo sin justa causa, siéndoles aplicable en otro caso lo dispuesto en el párrafo segundo del artículo 346".

15 Artículo 11.2 (LORTAD): "El consentimiento exigido en el apartado anterior no será preciso: ... d) Cuando la cesión que deba efectuarse tenga por destinatario el Defensor del Pueblo, el Ministerio Fiscal o los Jueces o Tribunales, en el ejercicio de las funciones que tienen atribuidas".

16 Artículo 16 (Código Deontológico): "Con discreción, exclusivamente ante quien tenga que hacerlo, en sus justos y restringidos límites y, si lo estimara necesario, solicitando el asesoramiento del Colegio, el médico podrá revelar el secreto en los siguientes casos: (a) Por imperativo legal...".
} 
Eticamente el secreto médico profesional obliga al médico perito a no revelar más de lo necesario para el peritaje, así como a no revelar nada de lo que haya conocido si ha tenido acceso a la historia clínica que no sea estrictamente útil para documentar el informe pericial, así como a no divulgar dicho informe, limitándose a entregarlo solamente a quienes tuvieran derecho a él, incluyendo en ocasiones al propio interesado.

Todos los derechos del paciente se podrían reducir a dos que constituyen el núcleo esencial de la personalidad: el derecho del paciente a ser debidamente informado y el derecho a la confidencialidad de la información de interés sanitario que genera a lo largo de su vida. Derechos que tienen una relación directa con la historia clínica, documento en el que convergen intereses del paciente, de la administración sanitaria, del médico y, en ocasiones, de la administración de justicia.

La solicitud por parte de la Justicia de este documento puede atentar contra el mencionado artículo 18, párrafo I de nuestra Constitución. Asimismo, de la lectura de la historia clínica se deriva la posibilidad de obtener datos que pueden ser utilizados posteriormente en contra del sujeto (p. ej. un accidente de tráfico bajo los efectos del alcohol).

Pese a que el derecho de la autoridad judicial a acceder a la información y documentación clínica nunca se discute, debería ser objeto de una regulación más actual y acorde con los intereses del conflicto, dado que nuestras leyes de enjuiciamiento civil y criminal se publicaron en un contexto muy diferente del actual. Así por ejemplo, la naturaleza de la información clínica que puede necesitar un Juzgado o Tribunal para resolver un procedimiento judicial estará en función de la acción que se ejercite: una reclamación por responsabilidad civil del médico por mala praxis, una acción de reclamación por mal funcionamiento del servicio de salud, un procedimiento para declarar la incapacidad laboral de un trabajador, etc. Por ello, cuando las autoridades judiciales demandan la entrega de la historia clínica de un paciente para incorporarla, en bloque, a un procedimiento judicial, el médico tendrá derecho a exigir que se precise qué informes o datos de la misma se consideran necesarios por la autoridad judicial para el buen fin de la investigación. Así, por ejemplo, en Estados Unidos la American Medical Association insiste en la necesidad de determinar qué parte de historia o de información se precisa, de qué periodo de tiempo y el fin para el que se solicita.

La Recomendación del Consejo de Ministros del Consejo de Europa sobre Datos Médicos de 1997 marca tres principios básicos al respecto:

I.- Escrupuloso respeto al principio de reserva de la Ley. Todas estas cuestiones, por su excepcional importancia para la persona y para la sociedad, deben estar previstas en leyes, con las garantías que ello comporta, y no en normas de nivel meramente reglamentario. Sobre todo cuando se trata de establecer excepciones al consentimiento del paciente y el respeto al secreto médico.

2.- Toda información relativa a los datos médicos del paciente, en especial los que afectan de manera directa a su intimidad, debe ser obtenida, tratada y custodiada por profesionales de la salud.

3.- En casos excepcionales y para intereses generales muy relevantes previamente fijados por la Ley, se podrá prescindir del paciente para la utilización de sus datos sanitarios en beneficio de la sociedad.

¿Cuándo se van a intentar tales medidas entre nosotros? La protección de los derechos fundamentales de la persona solo tiene efectividad si se produce a través de normas jurídicas. Es el tiempo de que el legislador intervenga para que se incorpore a nuestro ordenamiento jurídico la normativa precisa que permita una regulación de la actividad pericial que no colisione con los derechos fundamentales del paciente. 


\section{BIBLIOGRAFÍA:}

-Alvarez-Cienfuegos Suárez J.M., López Rodríguez 0.: Secreto médico y confidencialidad de los datos sanitarios. En De Lorenzo $R$. (coord.): "Formación en Responsabilidad Profesional". Asociación Española de Derecho Sanitario.

-Criado del Río M.T.: "Aspectos médico-legales de la historia clínica". Colex. Madrid. 1999.

-Criado del Río M.T.: "Valoración médico-legal del daño a la persona". Colex. Madrid. 1999.

-De Lorenzo R.: "El consentimiento informado en cirugía ortopédica y traumatológica". Editores Médicos S.A. Madrid. 1997.

-De Lorenzo R. (coor.): "Responsabilidad Legal del Profesional Sanitario". Asociación Española de Derecho Sanitario. Madrid. 2000.

-Gisbert Calabuig J.A.: "Medicina Legal y Toxicología". 5 a edición.
Masson. Barcelona. 1998

-Martínez Pereda J.M., De Lorenzo R.: "Los Médicos y el nuevo Código Penal". Editores Médicos S.A. Madrid. 1997.

-Romeo Casabona C.M. (coor): "Derecho biomédico y bioética". Editorial Comares. Granada. 1998

-Rovira Barberá M.: Confidencialidad e historia clínica informatizada. JANO, 1998, LV: I673-I674.

-Sánchez González M.: Intimidad y secreto médico. En VI Congreso Nacional de Derecho Sanitario. Madrid. 2000.

-Serrat Moré D. (coor): "Manual de normativa Médica y Sanitaria". Colex. Madrid. 1998.

-Vegue González M., Alvaro Brun E.: El secreto médico en instituciones penitenciarias. Rev. Esp. Sanid. Penit., 2001, 3: 22-29. 